\title{
Eleições 2018 e escritas na mídia: processos de produção de sentidos do enunciado "\#ELENÃO"
}

\section{Elections 2018 and written in the media: sense production processes of the "\# ELENÃO"}

\author{
Maria Deusa Brito de Sousa Apinagé ${ }^{1}$ \\ Janete Silva dos Santos ${ }^{2}$
}

Recebido em: 24/10/2019

Aprovado em: 13/04/2020

Publicado em: 30/06/2020

Resumo: Este artigo apresenta uma reflexão sobre processos de produção de sentidos do enunciado \#ELENÃO, texto escrito circulado nas mídias sociais durante a campanha de candidatura do deputado federal Jair Bolsonaro (PSL) à presidência da República. A escrita nas redes sociais, em período eleitoral, favorece aos internautas o apelo a slogans instantâneos que sintetizam ideários que os unem fortemente em um propósito conforme sua inclinação sociopolítica. A fim de analisar o funcionamento discursivo dessa materialidade significante, buscamos compreendê-la a partir das contribuições da Análise de Discurso de linha francesa pecheutiana, teoria de interpretação que pode ser aplicada a diferentes textos, em específico, neste trabalho, ao enunciado em questão. As reflexões produzidas no percurso de análise, sobre o enunciado \#ELENÃO, apontam como os sentidos se constroem continuamente e não se fecham, numa relação entre a repetição e a possibilidade de o sentido ser outro, visto que, neste caso específico, essa materialidade está sujeita sempre a novas leituras e interpretações.

Palavras-chave: Análise de Discurso; Escrita Midiática; \#ELENÃO

\begin{abstract}
This paper presents a reflection on the meaning production processes of the utterance \# ELENÃO, written text circulated on social media during the federal congressman Jair Bolsonaro (PSL) candidacy campaign for the presidency of the Republic. The writing in social networks, during the electoral period, favors Internet users the appeal to instant slogans that synthesize ideas that link them strongly in a purpose according to their sociopolitical inclination. In order to analyze the discursive functioning of this significant materiality, we seek to understand it from the contributions of the Pecheut's Discourse Analysis, a theory of interpretation that can be applied to different texts, specifically in this paper, to the statement in question. The reflections produced in the course of analysis on the statement \# ELENÃO, point out how the senses are continuously built and not closed, in a relationship between repetition and the possibility of meaning being another, since in this specific case this materiality is always subject to new readings and interpretations.
\end{abstract}

Keywords: Discourse Analysis; Media Writing; \#ELENAO.

1. Mestranda em Letras pela Universidade Federal do Tocantins. Graduação em Letras pela Universidade Federal do Tocantins. Atualmente é professora da Educação Básica - Secretaria da Educação e Cultura. ORCID: 0000-0002-5119-1383 E-mail: deusa.gui@hotmail.com

2. Mestrado e Doutorado em Linguística Aplicada pela Unicamp. Licenciada plena em Letras. Docente (adjunto 4) da Universidade Federal do Tocantins. ORCID: 0000-0003-2823-6114 E-mail:

janetesantos35@yahoo.com 


\section{BRITO DE SOUSA APINAGÉ, M.D.D.; SILVA DOS SANTOS, J.}

\section{INTRODUÇÃO}

O ensino nas escolas brasileiras tem como uma das ferramentas fundamentais o uso de livros didáticos (LD), os quais recortam textos de materialidades que circulam em determinados espaços sociais, dando, por isso, preferência a umas e apagando outras, quer para o ensino de leitura, quer para o ensino de escrita (produção de texto), o que em tese é definido pelo projeto pedagógico da obra, em atendimento à demanda das áreas que pretende atingir. No ensino de língua portuguesa, por exemplo, também certos gêneros e temáticas são privilegiados, outros não, porém, uma vez incorporados ao LD sofrem perdas em seu funcionamento, visto a seleção e a estratégia de leitura ou de escrita se darem no processo de didatização, próprio do trabalho escolar, o que resulta em descaracterização, total ou parcial, do gênero focalizado (SANTOS e SANTOS, 2019, p.202).

Temos como pressuposto que, no processo de letramento promovido pela escola, leitura e escrita são práticas indissociáveis. Assim, na perspectiva discursiva contemplada neste trabalho, a da Análise de discurso francesa (AD), pensar em condições de produção da leitura é também pensar nas condições de produção do texto escrito, seja ele verbal, seja ele híbrido (verbal e não-verbal), mormente os textos criados ou compartilhados nas plataformas digitais. Por conta disso, acreditamos que a análise aqui empreendida pode contribuir para a discussão quanto a abordagens na escola relativas ao trabalho de leitura ou de escrita de textos (de gêneros incluindo os menos formais e com temáticas do cotidiano dos cidadãos) produzidos por sujeitos de diferentes camadas sociais, veiculados no espaço cibernético, especialmente nas redes sociais.

Entendemos que as mídias sociais são um espaço carregado de sentidos. De uma perspectiva discursiva, buscamos compreender, neste trabalho, os processos de constituição, de formulação e de circulação dos sentidos do/no enunciado \#ELENÃO (re)significado pelo movimento conhecido como "Mulheres Unidas contra Bolsonaro". Esse movimento teve ampla repercussão por meio do Facebook, criado no dia 30 de agosto de 2018 e culminou no dia 29 de setembro, deste mesmo ano, com protestos pelas ruas de todos os estados brasileiros, expandindo-se para outros países. As manifestações tiveram o apoio e a participação de movimentos sociais, de grupos feministas, de partidos políticos e de celebridades nacionais e internacionais.

O principal objetivo do movimento foi protestar contra a candidatura do deputado federal, Jair Bolsonaro (PSL), à presidência da República. Segundo as organizadoras do movimento, os protestos foram motivados pelo discurso misógino do candidato e, 


\section{BRITO DE SOUSA APINAGÉ, M.D.D.; SILVA DOS SANTOS, J.}

também, por suas ameaças à democracia, além das declarações machista, racista, homofóbica e autoritária que não se furtou a efetivar.

Em reação ao movimento \#ELENÃO, foram organizados protestos a favor de Jair Bolsonaro, chamado Movimento \#ELESIM. Foram manifestações populares que ocorreram pelo Brasil, com o intuito de manifestar apoio a candidatura de Jair Bolsonaro à presidência. Como podemos observar, os apoiadores do candidato Bolsonaro também não utilizam o nome próprio dele, optaram por um enunciado que marcasse sua oposição em relação ao outro grupo. É importante ressaltar que as manifestações aconteceram no mesmo dia, porém, com objetivos diferentes. Enquanto o primeiro grupo protestava contra a candidatura de Jair Bolsonaro, o segundo se manifestava a favor.

Tendo em vista os pressupostos teóricos oriundos da Análise de Discurso de linha francesa, este artigo se propõe a refletir sobre os processos de constituição, de formulação e de circulação dos sentidos do/no enunciado \#ELENÃO, que circulou nas mídias sociais, durante o período das eleições presidenciais de 2018. Segundo informações da página "Mulheres Unidas contra Bolsonaro", o grupo é composto por 2.514.295 membros, 15 administradores e 44 moderadores, e tem como finalidade:

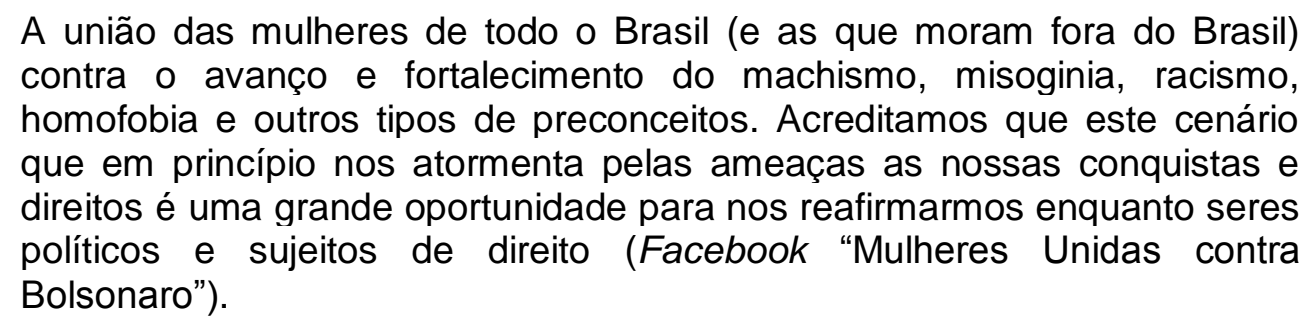

Para a nossa análise, selecionamos, como recorte discursivo, três textos, construídos a partir de imagens com signos verbais e não verbais, que tiveram grande circulação nas mídias. Desse modo, este trabalho se justifica por discutir os efeitos de sentido possíveis de serem produzidos a partir do enunciado em questão.

\section{Contribuições teórico-metodológicas da Análise de Discurso}

Tomamos como corpus três imagens publicadas nas mídias sociais, e as compreendemos como enunciados, quando nos propomos a analisá-las a partir da perspectiva teórica de Michel Pêcheux, pois, como textos (enunciados a interpelar os sujeitos) que materializam discursos/discursividades, atendem às características concebidas pelo filósofo. Ao discutir sobre o enunciado, Michel Pêcheux (2015), considera que, 
Todo enunciado é intrinsecamente suscetível de tornar-se outro, diferente de si mesmo, se deslocar discursivamente de seu sentido para derivar para um outro (a não ser que a proibição da interpretação própria ao logicamente estável se exerça sobre ele explicitamente). Todo enunciado, toda sequência de enunciados é, pois, linguisticamente descritivel como uma série (léxico-sintaticamente determinada) de pontos de deriva possíveis, oferecendo lugar a interpretação. É nesse espaço que pretende trabalhar a análise de discurso (PÊCHEUX, 2015 p. 53).

Nesse sentido, há a possibilidade mesma de o sentido ser sempre outro, devido à deriva na interpretação, já que essa possibilidade se encontra em toda e qualquer manifestação de linguagem, pois não existe sentido sem interpretação. Há de se considerar que são possíveis diferentes gestos de interpretação, visto que as diferentes linguagens ou formas de linguagem significam de formas diferentes, de acordo com sua materialidade (ORLANDI, 1996). Diferentemente de outras teorias da linguagem, a Análise de Discurso relaciona a interpretação com a questão da ideologia e, nessa perspectiva, considera a interpretação em duas instâncias: a) como parte da atividade do analista e b) como parte da atividade do sujeito.

$\mathrm{Na}$ primeira instância, que considera a interpretação como parte da atividade do analista, este deve considerar que "a linguagem não é transparente, e interpretar não é atribuir sentido, mas expor-se à opacidade do texto, ou seja, é explicitar como um objeto simbólico produz sentidos" (ORLANDI, 2017, p. 28). Desse modo, o analista não atravessa a linguagem para buscar sentido no que há por trás do que foi dito; também não questiona o que aquilo quis dizer, mas pergunta como aquilo significa, tendo em vista que a linguagem, assim como o sujeito, não é transparente. Na segunda instância, que considera a interpretação como parte da atividade do sujeito, pode-se considerar a interpretação como uma injunção. Em sua teorização, Orlandi (2017) enfatiza que:

[f]ace a qualquer objeto simbólico o sujeito é instado a interpretar, pois ele se encontra na necessidade de "dar" sentido. O que é dar sentido? Para o sujeito que fala, é construir sítios de significação, é tornar possíveis gestos de interpretação (ORLANDI, 2017, p. 28).

Desse modo, é pressuposto, nessa perspectiva, que é inerente ao sujeito conceituar, interpretar o que está em sua volta, buscar fechar o sentido. Logo, a AD (des)constrói a ilusão da transparência e do fechamento do sentido na interpretação. Por ser heterogêneo, o sentido não se fecha, abrindo sempre para a possibilidade de ser outro.

A Análise de Discurso (AD) se difere de outras teorias pelo modo como trabalha a interpretação, problematizando a opacidade da linguagem, a sua não evidência, a não

Revista do SELL, Uberaba/MG (online) - V. 9 n. 1, p. 72-87, jan. /jun. - 2020. 


\section{BRITO DE SOUSA APINAGÉ, M.D.D.; SILVA DOS SANTOS, J.}

transparência. Leva em consideração a linguagem como estrutura e acontecimento, considera, também, o acaso, o equívoco, a falha. Nessa perspectiva, foram construídos dois dispositivos para ter acesso à materialidade da linguagem, à sua discursividade: dispositivo teórico da interpretação e dispositivo analítico da interpretação. Logo, vejamos o que Orlandi (2017) pontua acerca das diferenças entre dispositivo teórico da interpretação e dispositivo analítico da interpretação. De acordo com ela,

O dispositivo teórico é constituído pelas noções e conceitos que constituem os princípios da análise de discurso: a noção de discurso como efeitos de sentidos, a noção de formação discursiva, a de formação ideológica, o interdiscurso, etc. O dispositivo teórico vai determinar o dispositivo analítico. Ele orienta o analista em como observar o funcionamento discursivo. É o dispositivo teórico que faz o deslocamento de uma leitura tradicional para uma leitura que chamamos sintomática: a que estabelece uma escuta que coloca em relação o dizer com outros dizeres e com aquilo que ele não é mas poderia ser. (ORLANDI, 2017, p. 29-30)

Sustentada por dispositivos teóricos e analíticos, a AD direciona para novas formas de ler, para escutas que vão além das evidências, para novos gestos de interpretação que consideram a opacidade da linguagem, a historicidade, a constituição do sujeito pela ideologia. Sobre o dispositivo analítico da interpretação Orlandi (2017) enfoca que:

Determinado pelo dispositivo teórico, o dispositivo analítico por sua vez vai depender da questão do analista, da natureza do material analisado, do objetivo do analista da região teórica em que se inscreve o analista (linguística, história, antropologia, literatura etc.). (ORLANDI, 2017, p. 30)

Considerando que em toda interpretação devemos levar em consideração aquilo que é dito naquele momento, o que já foi dito e esquecido, bem como aquilo que não foi dito, mas faz sentido, visto que se mostra relevante considerar os três momentos que contemplam os processos de produção do discurso e que conduzirão as análises a serem desenvolvidas neste artigo. Orlandi (2015) menciona esses três processos como igualmente relevantes, uma não se sobrepõe, em importância, a outra.

1. Sua constituição, a partir da memória do dizer, fazendo intervir o contexto histórico-ideólogico mais amplo;

2. Sua formulação, em condições de produção e circunstâncias de enunciação específicas;

3. Sua circulação que se dá em certa conjuntura e segundo certas condições.

O momento da constituição tem a ver com o interdiscurso e é figurado como um eixo vertical formado por todos os dizeres já ditos e esquecidos. A constituição determina a formulação, tendo em vista que só é possível formular se nos lançarmos na perspectiva 


\section{BRITO DE SOUSA APINAGÉ, M.D.D.; SILVA DOS SANTOS, J.}

daquilo que é dizível. Conforme Orlandi (2015, p. 31), "todo dizer, na realidade, se encontra na confluência de dois eixos: o da memória (constituição) e o da atualidade (formulação), e é desse jogo que tiram seus sentidos".

Já o momento da formulação corresponde ao intradiscurso e é representado em um eixo horizontal. É o que dá vida à linguagem, pois, conforme Orlandi (2012, p. 193), "formular é textualizar palavras, é dar corpo aos sentidos", visto que o sujeito é interpelado a construir sentido. Sendo o simbólico o registro que constitui o sujeito na/pela linguagem. Nesse contexto, a formulação compreende:

O momento em que o sujeito diz o que diz. Em que se assume autor. Representa-se na origem do que diz com sua responsabilidade, suas necessidades. Seus sentimentos, seus desígnios, suas expectativas, sua determinação. Pois, não esqueçamos, o sujeito é determinado pela exterioridade mas, na forma-sujeito histórica que é a do capitalismo, ele se constitui por esta ambiguidade de, ao mesmo tempo, determinar o que diz. A formulação é o lugar em que esta contradição se realiza. Ela é o acontecimento discursivo pelo qual o sujeito articula manifestamente seu dizer. Dá o contorno material ao dizer instaurando o texto (ORLANDI, 2012, p.10).

A circulação, ou trajetos dos dizeres, não apresentam neutralidade. Para Orlandi (2012, p. 11-12), "os 'meios' não são nunca neutros. Ou seja, os sentidos são como se constituem, como se formulam e como circulam (em que meios e de que maneira: escritos em uma faixa, sussurrados como boato, documento, carta, música etc)". Para a autora, as três instâncias se fazem igualmente relevantes e não há por que, no momento da análise, privilegiar uma em detrimento da outra. Portanto, a ordem de apresentação dessas instâncias só se faz por necessidade teórica ou por questões metodológicas.

Levando em consideração o nosso material de análise, que ainda apresentaremos, neste artigo, a terceira imagem traz textualizado o corpo de uma mulher. Conforme Ferreira (2013, p. 99), "[u]m modo de refletir sobre o corpo é concebê-lo numa tríplice condição: (i) como lugar de observação do sujeito, (ii) como objeto e (iii) como ferramenta". Desde tempos remotos o corpo é visto sob essas condições por meio de expressões artísticas, tais como a pintura e a escultura, e essa visão vem trilhando um longo percurso que atravessa o tempo e o espaço e chega à contemporaneidade, mesmo que explorado de formas diferentes das anteriores. Ainda de acordo com Ferreira (2013):

É possível conceber o corpo como um lugar de simbolização, um lugar falado pelas palavras, pela língua. Portanto, podemos considerar que essa fala produzida com o corpo acaba por nele se inscrever, afetando-o. Vale dizer: a inscrição do sujeito no mundo se faz através do corpo (FERREIRA, 2013, p. 100). 


\section{BRITO DE SOUSA APINAGÉ, M.D.D.; SILVA DOS SANTOS, J.}

Nesse sentido, entendemos o corpo como materialidade significante. $O$ corpo que fala, que é falado, que representa, que é representado, que significa, que é significado. Em suma, o corpo como matéria-prima moldado pela linguagem, o corpo discursivo.

A segunda imagem, a ser foco de nossas análises, traz textualizado o rosto, também, de uma mulher. Conforme enfoca Jean-Jacques Courtine (2018 p. 126), "o corpo, o rosto, o gesto e a expressão tornaram-se objetos essenciais do espetáculo político". Em se tratando do cenário político de 2018 no Brasil, as imagens textualizadas nos rostos e nos corpos das pessoas, em especial, das mulheres, no contexto aqui abordado, foram o figurino principal nesse espetáculo. Ainda segundo Courtine (2018, p. 118), "uma imagem, um gesto, vale mil palavras". Embora tenhamos selecionado, como recortes, apenas três imagens (textos) para a análise, há um número incontável delas disponível nas mídias carregadas de sentidos que também poderiam ser objeto de nossa análise.

Considerando como acontecimento as manifestações de 29 de setembro de 2018, ocorridas no Brasil, tida como as maiores já realizadas por mulheres na história do país, convocadas pelas feministas nas redes sociais com a hashtag "Ele não" (\#ELENÃO), contra o então candidato à Presidência do Brasil, Jair Messias Bolsonaro (PSL), é possível relacionar ao acontecimento de 10 de maio de 1981, em Paris, quando, às 20h, a imagem do presidente François Mitterand, presidente da República Francesa, aparece nos televisores acompanhada do seguinte enunciado: "On a gagné " [Ganhamos."] (PÊCHEUX, 2015). Mesmo em condições de produção diferentes, esses acontecimentos funcionam em certa regularidade. Ambos, apesar de circularem em tempos e lugares diferentes, envolvem posições parecidas: a presidência da República. O primeiro acontece antes das eleições, o segundo, no momento da vitória.

O acontecimento que culminou no dia 29 de setembro de 2018, assim como o que aconteceu no dia 10 de maio de 1981, é o resultado de um percurso que começa bem antes. No nosso recorte, das redes sociais para as ruas, as manifestações de 29 de setembro foram organizadas por feministas que se mobilizaram e foram responsáveis pela criação do grupo do Facebook "Mulheres Unidas contra Bolsonaro", que em menos de três dias reuniu mais de 700 mil membros, especialmente mulheres.

Assim, surgiu o movimento "Ele não" (marcado pela hashtag \#ELENÃO nas redes sociais). A ideia era criar uma campanha para demonstrar repúdio ao candidato que apresentava comportamento tido como inapropriado para alguém que pretendia se tornar o presidente de uma nação. O discurso desse grupo ecoou e atingiu inúmeras(os) 


\section{BRITO DE SOUSA APINAGÉ, M.D.D.; SILVA DOS SANTOS, J.}

adeptas(os) que se identificaram com tal posicionamento contra o então candidato, Jair Messias Bolsonaro. Por outro lado, o discurso de Bolsonaro, também, encontrava adeptos que defendiam as mesmas coisas que ele.

Visando a impedir que o uso do nome Bolsonaro, nas redes sociais, gerasse maior visibilidade por conta dos algoritmos utilizados na Internet, mesmo que estivesse associado a críticas, optou-se pelo uso da \#ELENÃO. Desse modo, a substituição do substantivo próprio Bolsonaro pelo pronome pessoal Ele, seguido do advérbio de negação (Não), manifesta também uma posição de recusa do enunciador a tudo o que representa o candidato do PSL à Presidência da República, por materializar a ruptura de vieses políticos entre os sujeitos que enunciam e defendem a hashtag \#ELENÃO e o candidato, sua postura política. Ou seja, esse apagamento do nome do candidato, essa recusa de a ele se referir sem referência a seu nome, materializa embates entre formações discursivas em disputa.

Com base nessas considerações, tomamos a materialidade do enunciado \#ELENÃO como manifestação material do discurso midiático, com suas formas, suas marcas, sua historicidade e sua ideologia, a ser analisada, dando-se ênfase aos três processos aqui definidos.

\section{Análise discursiva do enunciado \#ELENÃO nas imagens em que aparece}

A partir das observações citadas anteriormente, podemos, então, iniciar a análise do nosso corpus. Vamos, neste mo(vi)mento de interpretação, através dos pressupostos pecheuxtianos, caracterizar o nosso material simbólico e, em seguida, efetuar gestos de interpretação com o fim de realizar uma leitura discursiva que vá além da materialidade linguística, elencando, assim, possíveis efeitos de sentido. Para tanto, vejamos a primeira imagem: 


\section{Imagem 1}

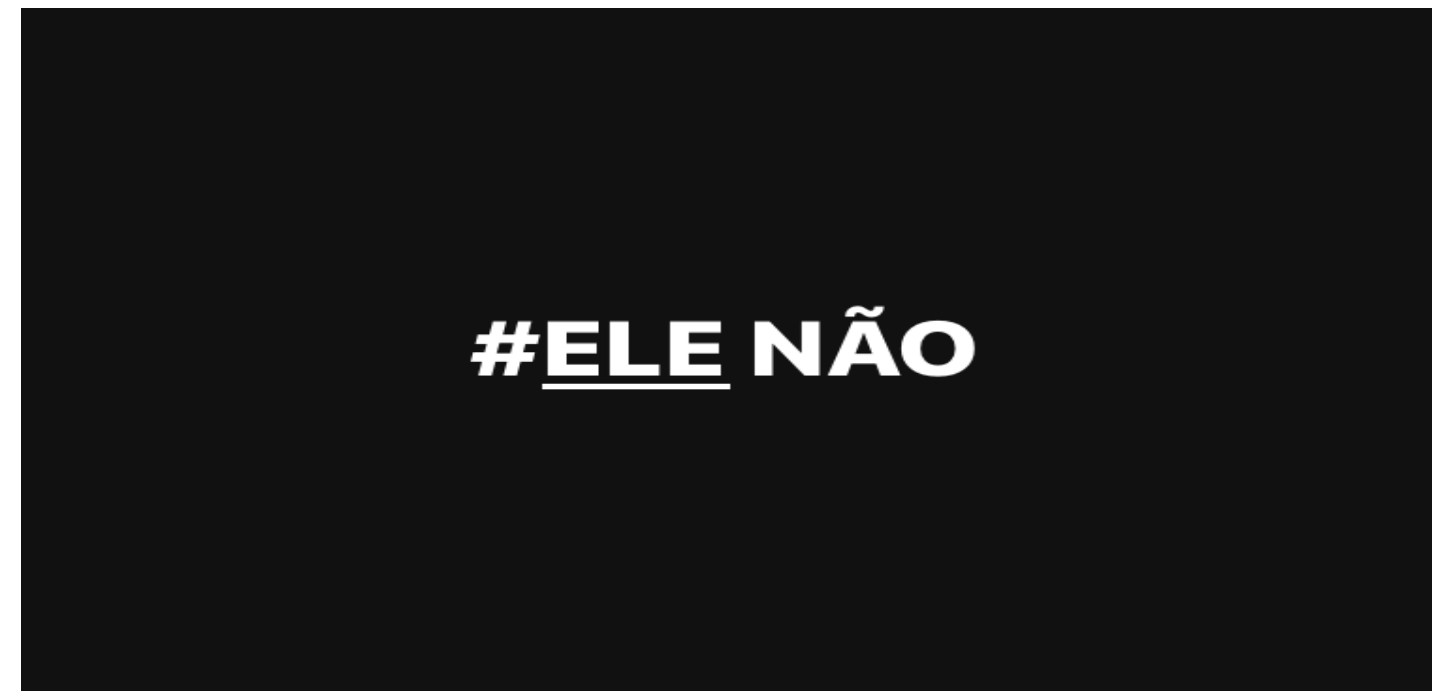

Fonte: Página do Facebook do grupo "Mulheres Unidas contra Bolsonaro"

$\mathrm{Na}$ imagem com fundo preto e letras brancas, no centro, temos o enunciado \#ELE NÃO, escrito em caixa alta, com um sublinhado na palavra "ELE". De acordo com as convenções de escrita na Internet, ao utilizar-se de caixa alta na escrita, infere-se que o locutor esteja gritando, vociferando. Depreendemos, assim, que o locutor/autor grita, clama para que a sua voz seja ouvida/vista. Para compreender o sentido da hashtag, fazse necessário a análise do texto imagético em todas as suas marcas significantes.

Hashtag é uma formulação comumente usada pelos usuários das mídias sociais, na Internet, e consiste em uma palavra-chave precedida pelo símbolo \#, conhecido popularmente no Brasil por "jogo da velha" ou "quadrado". As hashtags permitem atingir um número maior de pessoas com a sua publicação e criam uma interação dinâmica do conteúdo, por meio de links, que facilitam a localização pelos demais usuários da mídia social que estão interessados no mesmo assunto publicado. Com o uso da hashtag em uma publicação, o conteúdo ficará disponível para qualquer pessoa que acesse o mesmo hashtag sobre o assunto, permitindo-a comentar, compartilhar ou curtir o conteúdo.

A partir dessas considerações, entendemos que os sentidos não estão somente nas palavras, mas em sua relação com a exterioridade, ou seja, tem a ver com o que é dito aqui, mas também em outros espaços, por outras pessoas, em outros momentos, em outras condições de produção. A cor preta no fundo da imagem carrega em si uma memória. Além de sentidos relacionados com a morte, a solidão, o medo, o isolamento, a tristeza, o luto, no meio político, tem a ver com o fascismo, com os conservadores, com a 


\section{BRITO DE SOUSA APINAGÉ, M.D.D.; SILVA DOS SANTOS, J.}

direita. Já a cor branca, nas letras do enunciado, representa, na cultura ocidental, paz, pureza, alegria, calma e liberdade.

Levando em consideração o contexto político de 2018, essa oposição entre as cores traz dois efeitos a elas inerentes: 1 . A cor preta mostra a recusa em relação a um dos candidatos à presidência, pois este faz supor a representação do fascismo, do medo, do retrocesso, do perigo e de muitas outras ameaças. 2. A cor branca nas letras e a enunciação presentes no enunciado revelam outro efeito de sentido. A não eleição do candidato que produz ameaça à presidência representa a paz, a calma, o avanço, a tranquilidade.

Outro efeito de sentido que também é observado nessa imagem é o que há nos dois lados opostos representados e que produzem efeitos distintos, significa dizer que há uma tomada de posição por parte de quem produziu e/ou fez circular a imagem contra 0 candidato que faz supor ameaça e perigo aos eleitores.

A partir das análises feitas, fica explícito que a posição por parte de quem produziu e/ou fez circular, ou, ainda, compartilha dessa ideia, é de esquerda. Dessa forma, entendemos que ao propor essa "interpretação", estamos buscando ir além do que está dito.

Para evidenciar o que foi mencionado anteriormente, produzimos uma paráfrase desse enunciado. Em um caso hipotético, o fundo da imagem seria verde, as letras estariam escritas na cor amarela, representando as cores da bandeira brasileira, fazendo referência à pátria e o enunciado seria \#ELE SIM. Aqui os dizeres seriam outros. As palavras e as cores foram mobilizadas e produziram efeitos de sentidos diferentes. Os dizeres deixam marcas, pistas, vestígios que nos levam em uma direção que vai além da decodificação, além do interior, da transparência, do dito. Somos levados à exterioridade, à opacidade, ao não-dito, mas que poderia ser dito e não foi.

Por fim, tratamos do sublinhado na palavra ELE, entendendo-o como um acréscimo, um vestígio na nossa interpretação. O sublinhado, neste caso específico, serviu para dar dimensão, ênfase, destaque, na palavra. Essa dimensão nos leva à possibilidade de falar de forma diferente e de dizer a mesma coisa. Ou seja, ELE, na concepção da "esquerda", representa o perigo, a ameaça, o medo, o fascismo, a direita, enfim, O Bolsonaro. Dito de outra forma, \#BOLSONARO NÃO. Parafraseando Orlandi (2012), o acréscimo é o lugar onde o explícito é pressionado pelo implícito. 
BRITO DE SOUSA APINAGÉ, M.D.D.; SILVA DOS SANTOS, J.

Continuando o nosso trabalho de análise, consideremos, a seguir, a próxima imagem:

Imagem 2

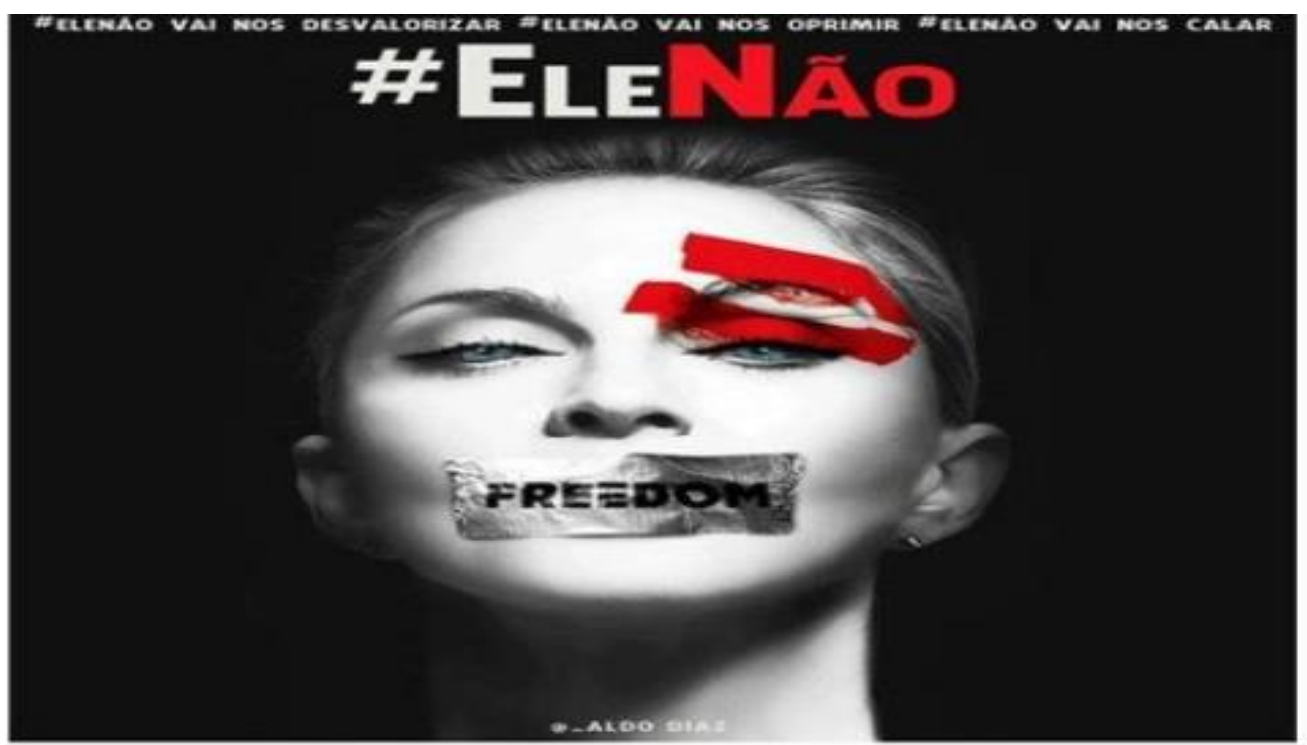

\#endfacism

Fonte: Aldo Diaz.

Tomando como base as condições de produção do discurso em seu contexto imediato, temos o enunciado \#ELENÃO popularizado por meio do movimento das "Mulheres Unidas contra Bolsonaro" com ampla repercussão a partir da divulgação de uma imagem nos stories do Instagram da celebridade internacional, Madonna. Cantora, atriz e produtora musical norte-americana, Madonna é considerada uma das maiores pop stars desde a década de 80 e uma das grandes responsáveis pela mudança de comportamento social no final do século XX.

Em termos de modos de circulação, os trajetos que um enunciado realiza na sociedade se dão por meio de conjunturas específicas, que, nesse caso, tem relação com o domínio midiático. No dia 28 de setembro de 2018, às 10:43, a cantora declara apoio ao movimento \#ELENÃO por meio de uma publicação feita em seu story do Instagram. As mensagens publicadas nos stories são apagadas automaticamente em 24 horas, caso não sejam destacadas na página principal. Em suma, o enunciado transita em meios nunca neutros e produz diferentes efeitos pelo modo como circula.

A imagem, constituída por texto verbal e não verbal, mostra o rosto da cantora com uma fita na boca com a palavra em inglês, freedom, que significa liberdade em português, além das hashtags \#ELENÃO VAI NOS DESVALORIZAR \#ELENÃO VAI NOS OPRIMIR \#ELENÃO VAI NOS CALAR \#ELENÃO. A imagem aparece em preto e branco, com 


\section{BRITO DE SOUSA APINAGÉ, M.D.D.; SILVA DOS SANTOS, J.}

destaque na palavra "Não", em duas linhas sobre o olho esquerdo e na palavra \#endfacism ("fim do fascismo"), que aparecem na cor vermelha, sobressai ainda, a cor azul dos olhos da cantora.

A cor negra no fundo da imagem, a hashtag na parte inferior \#endfacism que significa "fim do fascismo", em português, a menção à liberdade, a fita pregada na boca como sinal de repressão, as linhas vermelhas no olho, simbolizando a agressão física, evocam um imaginário concernente ao fascismo, regime autoritário que atua contra as liberdades individuais, por meio de perseguição, de censura, de uso de violência e é caracterizado por uma reação contra o movimento democrático. Esse modo de significar o momento político como fascista é marcado pela negação, a partir do enunciado \#ELE NÃO. Outro possível gesto de leitura a respeito das duas linhas vermelhas no olho da cantora pode ser relacionado à cultura indígena, na qual os nativos pintam-se com linhas vermelhas para irem à guerra. Assim, a imagem, remete a uma convocação à luta pelas causas em questão.

Além disso, a personalidade escolhida, para fazer a mensagem circular, não foi escolhida por acaso. Madonna é uma figura pública reconhecida internacionalmente por se engajar na defesa da liberdade sexual, do empoderamento feminino, apoio à causa LGBT, contra a homofobia, bem como por seu relacionamento com o movimento negro. São justamente esses os alvos das críticas e ataques realizados por Bolsonaro. Assim, tal contexto parece garantir uma empatia, por parte da cantora, à causa do movimento "Ele Não".

O contexto sócio-histórico implica a mobilização da memória e dos sentidos produzidos em outros lugares, em outras circunstâncias, em outros momentos, mas que significam na relação com o enunciado. Com efeito, tudo o que já foi dito sobre violência, opressão, medo, censura, está significando no enunciado. Desse modo, o enunciado evoca sentidos já ditos e esquecidos ou não ditos, mas que poderiam ter sido ditos.

Em se tratando do texto híbrido (verbal e não verbal) que constitui a imagem 2, é preciso considerar o equívoco próprio da linguagem, pois a cada enunciado (re)formulado a paráfrase é ressignificada, abrindo-se para novos sentidos (polissemia). Se, no Brasil, a cor vermelha remete ao partido que, no imaginário de grande parte dos eleitores, é um partido progressista, democrático e defensor do direito dos trabalhadores (PT), para outra parcela é o partido a se rejeitar, derrubar, pois acusado pela grande mídia como o de maior nível de corrupção, e adjetivado por outra parcela da sociedade de 'comunista'; já, nos EUA, a cor vermelha pode mobilizar outra memória discursiva, pois, no post divulgado 


\section{BRITO DE SOUSA APINAGÉ, M.D.D.; SILVA DOS SANTOS, J.}

por lá (mesmo tendo sido produzido por um brasileiro que já trabalhou com a artista norteamericana, cuja imagem consta no post), o vermelho pode estar remetendo a outras perspectivas, como à cor do símbolo do fascismo, por exemplo. Vale salientar que, atualmente, tem-se lá um presidente considerado de viés fascista por muitos de seus conterrâneos, devido a discursos racistas e genofóbicos, entre outros, por ele sustentado em algumas ocasiões. Não é de se desconsiderar também, para efeitos de sentido das cores usadas no post, que nos EUA a cor vermelha é representativa do partido republicano, do qual o atual presidente faz parte.

Por outro lado, ao mesmo tempo em que a imagem mobiliza os sentidos do fascismo, posiciona-se contra, fazendo presente a questão do fascismo. Ou seja, o uso das hashtags \#ELENÃO (VAI NOS DESVALORIZAR, VAI NOS OPRIMIR, VAI NOS CALAR) produz o efeito de reação como negação contra a desvalorização, a opressão e o silenciamento, como se o presidenciável não fosse realizar as ações ali expressas "desvalorizar, oprimir e calar". Por outro lado, se substituirmos a \#ELENÃO por \#BOLSONARO (VAI NOS DESVALORIZAR, VAI NOS OPRIMIR, VAI NOS CALAR) O efeito produzido é contrário, pois, nesse caso, Bolsonaro seria o agente da ação do verbo "VAl" produzindo o efeito esperado no uso da \#ELENÃO.

Imagem 3

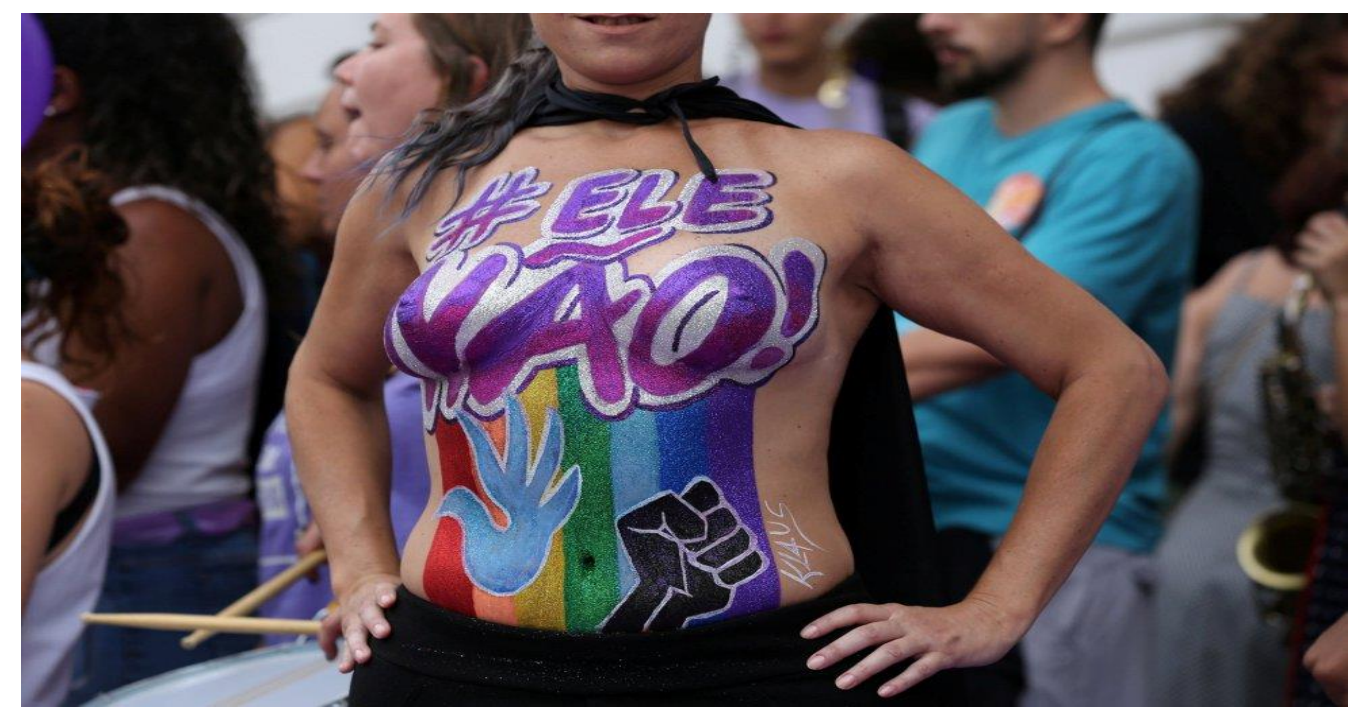

Fonte: Stringer, El País.

A terceira imagem traz textualizado o corpo de uma mulher no qual o texto verbal é constituído pelo enunciado \#ELE NÃO! E o texto não verbal é constituído pelo desenho da bandeira que representa o grupo de Lésbicas, Gays, Bissexuais, Travestis, Transexuais e Transgêneros (LGBT) pintada em tons que remetem às cores do arco-íris. 


\section{BRITO DE SOUSA APINAGÉ, M.D.D.; SILVA DOS SANTOS, J.}

Essas cores foram (re)significadas pelo grupo LGBT. No discurso religioso, o arcoíris simboliza o sinal da aliança feita por Deus com o homem de nunca mais destruir a terra com um dilúvio, exprime a presença e a fidelidade de Deus. Hoje é reconhecida mundialmente como o símbolo do orgulho, do reconhecimento e da cultura LGBT a nível mundial. A primeira versão da bandeira era composta por oito cores. A versão mais atual é composta por seis listras horizontais em seis cores diferentes e representam a diversidade humana. As cores representadas na imagem são sete: roxo (espírito), índigo (serenidade), turquesa (arte), verde (natureza), amarelo (sol), laranja (saúde) e vermelho (vida).

Os símbolos que representam o grupo LGBT associados ao enunciado \#ELE NÃO!, que aparecem na imagem, demonstram a resistência desse grupo à candidatura de Bolsonaro à presidência da República. Já que para eles, o candidato apresenta um discurso homofóbico, bem como propaga o ódio e o preconceito.

É importante ressaltar que as escolhas lexicais, bem como as escolhas imagéticas e as cores que compõem o corpus de nossa análise não foram feitas de forma aleatória, mas funcionam de forma a dar sentidos e, por mais que o enunciado se repita, ele nunca será o mesmo. As mesmas palavras podem significar de forma diferente, quando ditas por pessoas diferentes, em lugares diferentes, em momentos diferentes.

Nossa reflexão destaca aqui a AD como uma ferramenta de ampliação dos modos de ler textos de diferentes modalidades, bem como de ampliação na reflexão sobre as condições de produção das escritas híbridas possibilitadas pelas plataformas digitais, 0 que ocorre em velocidade e interação bem maior que a permitida nas práticas tradicionais. No caso específico deste artigo, situamos essa perspectiva como ferramenta para modos de ler textos híbridos, ou seja, textos que envolvem linguagem escrita verbal e não verbal, conforme os trabalhados no presente espaço.

Nosso dispositivo de análise focou o processo de produção de sentidos engendrado por diferentes signos, que envolvem palavras, gestos, formas e cores. Considerando o GT no qual nosso trabalho foi apresentado, podemos pontuar que 0 ensino de leitura na escola demanda lidar também com o processo de leitura de textos disseminados nas redes sociais, os quais não se conformam unicamente aos textos escritos tradicionais, mais comuns como objeto de estudo na tradição escolar. Esperamos assim ter contribuído não apenas para possíveis percursos de leitura do enunciado por nós privilegiado, como também para ressaltar o quanto a ideologia pode ser substancialmente problematizada nas materialidades disseminadas nas plataformas 


\section{BRITO DE SOUSA APINAGÉ, M.D.D.; SILVA DOS SANTOS, J.}

eletrônicas pela escola no ensino de língua portuguesa, com base em dispositivos da AD aqui mobilizados.

\section{CONSIDERAÇÕES FINAIS}

À luz das reflexões produzidas no trajeto de análise do enunciado \#ELENÃO, ratificamos que o enunciado na perspectiva da $A D$ é linguisticamente descritivel como uma série de deriva possível, oferecendo lugar à interpretação. Ele é sempre suscetível de ser/tornar-se outro. Assim, faz-se necessário compreender que os sentidos se constroem continuamente e não se fecham, numa relação entre a repetição e a possibilidade de o sentido ser outro, visto que, neste caso específico, essa materialidade está sujeita sempre a novas leituras e interpretações.

No caso de nossa análise, compreendemos que os sentidos produzidos a partir da constituição, da formulação e da circulação do enunciado \#ELENÃO dão vida a uma memória de retrocesso, de medo, de silenciamento e da ruptura de pré-construídos, tais como: direitos iguais entre homens e mulheres, liberdade de expressão, valorização e reconhecimento do papel da mulher na sociedade.

Os três textos, em linguagem híbrida (verbal e não-verbal), aqui chamados também de "imagens", que contêm o enunciado-base (Ele-Não), têm como tema central a rejeição à posição política de um candidato que ataca ideias progressistas, opondo-se ele, inclusive, às conquistas defendidas por inúmeros países, como a dos direitos humanos, considerados direitos básicos de todos os seres humanos, independente de tudo que os tipifique. $O$ enunciado-base foi analisado como paráfrase que, ao se repetir em diferentes condições de produção, produz novos sentidos ou sentidos ampliados, afetados por outros ingredientes da inscrição da posição-sujeito que o enuncia ou o propaga, conforme o percurso de análise possibilitou (re)construir.

Tal exercício aponta para as vantagens de se adotar a AD como uma das possibilidades de percurso reflexivo sobre as condições de produção tanto para a leitura como para a escrita, práticas indissociáveis, no ensino de língua portuguesa.

\section{REFERÊNCIAS}

COURTINE, J. J. As metamorfoses do Homo politicus. In: PIOVEZANI, C.; SARGENTINI, V. (Org.). Legados de Michel Pêcheux: inéditos em análise de discurso. São Paulo: Contexto, 2018. p.117-127.

DIAZ, Aldo. \#ELENÃO. Brasil, 28 de setembro de 2018. Instagram. Disponível em: https://www.instagram.com/p/BoRYCQqhpq4/?igshid=1ebb66e0n8s0e Acesso em 3/04/2019. 
BRITO DE SOUSA APINAGÉ, M.D.D.; SILVA DOS SANTOS, J.

FERREIRA, M. C. L. O corpo enquanto objeto discursivo. In: PETRI, V.; DIAS, C. (Org.). Análise de Discurso em Perspectiva: teoria, método e análise. Santa Maria, RS: Ed. da UFSM, 2013. p. 99-119.

MUCB, Mulheres Unidas contra Bolsonaro. Texto de descrição. Brasil, 30 de agosto de 2018. Facebook. Disponível em: https://www.facebook.com/groups/499414607198716/ Acesso em: 03/06/2019.

ORLANDI, E. P. Análise do discurso: princípios e procedimentos. 6a edição. Campinas, SP: Pontes, 2015.

ORLANDI, E. P Discurso e Texto: formulação e circulação dos sentidos. $4^{a}$ edição. Campinas, SP: Pontes, 2012.

ORLANDI, E. P Discurso e Textualidade. 3ª edição. Campinas, SP: Pontes, 2017.

ORLANDI, E. P Interpretação; autoria, leitura e efeitos do trabalho simbólico. $3^{\mathrm{a}}$ edição. Petrópolis, RJ: Vozes, 1996.

PÊCHEUX, M. O discurso: estrutura ou acontecimento. $7^{\text {a }}$ edição. Campinas, SP: Pontes Editores, 2015.

SANTOS, J. S.; SANTOS A. S. Leitura mediada por gêneros de jornal eletrônico e sustentabilidade: reflexões iniciais. Rev. FSA, Teresina-PI, v. 16, n. 3, art. 10, p. 185210, mai./jun. 2019.

STRINGER. Jornal El País. \#ELENÃO. 30 de setembro de 2019. https://brasil.elpais.com/brasil/2018/09/30/album/1538260378_408372.html\#foto_gal_12 Acesso em: 07/05/2019.

\section{Como citar este artigo (ABNT)}

BRITO DE SOUSA APINAGÉ, M.D.; SILVA DOS SANTOS, J. Eleições 2018 e escritas na mídia: processos de produção de sentidos do enunciado "\#ELENÃO". SELL, Uberaba, MG, v. X, n. X, p. XXX-XXX, 2019. Disponível em: <inserir link de acesso>. Acesso em: inserir dia, mês e ano de acesso. DOI: inserir link do DOI.

Como citar este artigo (APA)

Brito de Sousa Apinagé, M.D. \& Silva dos Santos, J. (2020). Eleições 2018 e escritas na mídia: processos de produção de sentidos do enunciado "\#ELENÃO". SELL, X(X), XXXXXX. Recuperado em: inserir dia, mês e ano de acesso de inserir link de acesso. DOI: inserir link do DOI. 